\title{
Measurements of photolyzable chlorine and bromine during the Polar Sunrise Experiment 1995
}

\author{
G.A. Impey, P.B. Shepson, ${ }^{1}$ D.R. Hastie, L.A. Barrie ${ }^{2}$ \\ Department of Chemistry and Centre for Atmospheric Chemistry, York University, Ontario, Canada
}

\author{
K.G. Anlauf \\ Atmospheric Environment Service, Toronto, Ontario, Canada
}

\begin{abstract}
We report measurements of rapidly photolyzable chlorine ( $\mathrm{Cl}_{\mathrm{p}}$; e.g., $\mathrm{Cl}_{2}$ and $\left.\mathrm{HOCl}\right)$ and bromine $\left(\mathrm{Br}_{\mathrm{p}}\right.$; e.g., $\mathrm{Br}_{2}$ and $\left.\mathrm{HOBr}\right)$ in the high Arctic using a newly developed photoactive halogen detector (PHD). Ground level ambient air was sampled daily from mid-February through mid-April in the Canadian Arctic at Alert, Northwest Territories $\left(82.5^{\circ} \mathrm{N}, 62.3^{\circ} \mathrm{W}\right)$, as part of the Polar Sunrise Experiment (PSE) 1995. Concentrations of "total photolyzable chlorine" varied from $<9$ to $100 \mathrm{pptv}$ as $\mathrm{Cl}_{2}$ and that of "total photolyzable bromine" from $<4$ to $38 \mathrm{pptv}$ as $\mathrm{Br}_{2}$. High concentration episodes of chlorine were observed only prior to sunrise (March 21), while high concentration episodes of bromine were measured throughout the study. The high concentrations of photolyzable chlorine and bromine prior to sunrise suggest a "dark" production mechanism that we assume yields $\mathrm{Cl}_{2}$ and $\mathrm{Br}_{2}$. An inverse correlation of bromine with ozone is clearly present in one major ozone depletion episode at the end of March. A trajectory analysis, taken with the differences in measured levels of photolyzable chlorine and bromine after sunrise, imply different production mechanisms for these two types of species. A steady state analysis of the data for one ozone depletion episode suggests a $[\mathrm{Br}] /[\mathrm{Cl}]$ ratio in the range 100-300. The high concentrations of photolyzable bromine after sunrise imply the existence of a precursor other than aerosol bromide.
\end{abstract}

\section{Introduction}

The dramatic loss of surface layer ozone at sunrise has been observed in the high Arctic for several years. The episodes occur with the onset of polar sunrise and are associated with large increases in the amount of filterable bromine [Barrie et al., 1988]. Bromine and chlorine atom chemistry has been implicated as the cause of the $\mathrm{O}_{3}$ destruction episodes. Evidence for halogen atom chemistry has come from measurements of non-methane-hydrocarbons (NMHC) [Jobson et al., 1994], $\mathrm{BrO}$ [Hausmann and Platt, 1994], organic nitrates [Muthuramu et al., 1994] as well as organic and inorganic bromine compounds [ $\mathrm{Li}$ et al., 1994], made during the Polar Sunrise Experiment 1992. Similar observations have been reported by Solberg et al. [1996], who find that ozone at Spitsbergen can be depleted from the surface to as high as $2 \mathrm{~km}$.

Modeling studies [Barrie et al., 1988; McConnell et al., 1992; Fan and Jacob, 1992; Tang and McConnell, 1996] have shown that for the observed ozone depletions, the $\mathrm{Cl}$ and $\mathrm{Br}$ atoms present could originate from a photochemically active "seed" (such as $\mathrm{CHBr}_{3}$ ) and that rapid recycling processes can then maintain the catalytic cycle.

To improve our understanding of the halogen atom chemistry occurring in the troposphere, reliable measurements of

\footnotetext{
INow at Department of Chemistry and Department of Earth and Atmospheric Sciences, Purdue University, West Lafayette, Indiana.

${ }^{2}$ Also at Atmospheric Environment Service, Toronto, Ontario, Canada.

Copyright 1997 by the American Geophysical Union.

Paper number 97JD00851.

0148-0227/97/97JD-00851\$09.00
}

photolytically active halogen species such as $\mathrm{Cl}_{2}, \mathrm{Br}_{2}, \mathrm{HOCl}$, and $\mathrm{HOBr}$ are clearly needed. Recent measurements of inorganic chlorine, which include $\mathrm{Cl}_{2}$ and $\mathrm{HOCl}$, have been made in the marine boundary layer at Virginia Key, Florida [Pszenny et al., 1993], and over eastern North America [Maben et al., 1995] using a tandem mist chamber described by Keene et al., [1993]. However, there have as yet been no measurements of $\mathrm{Br}_{2}\left(\right.$ or $\mathrm{Cl}_{2}$ ) in the Arctic, largely as a result of the lack of suitable analytical methodologies. Here we report the first measurements of photolytically active bromine $\left(\mathrm{Br}_{2}\right.$ and $\left.\mathrm{HOBr}\right)$ and chlorine $\left(\mathrm{Cl}_{2}\right.$ and $\mathrm{HOCl}$ ) in surface air at Alert, Northwest Territories Canada $\left(82.5^{\circ} \mathrm{N}, 62.3^{\circ} \mathrm{W}\right)$, using a newly developed method, the photoactive halogen detector (PHD). This method is described in detail by Impey et al. [this issue].

\section{Experimental Procedures}

The Polar Sunrise Experiment 1995 (PSE 95) was conducted at Alert, Canada, on northern Ellesmere Island $\left(82.5^{\circ} \mathrm{N}, 63.2^{\circ} \mathrm{W}\right)$ from February 20 to April 15, 1995. Measurements of photolyzable chlorine and bromine were conducted each day at the Special Studies Laboratory (SSL), situated on a plateau approximately $6 \mathrm{~km}$ SSW of the Canadian Forces Station, while ozone and meteorological data were measured continuously from the Baseline Air Pollution Monitoring Network (BAPMoN) laboratory situated within $1 \mathrm{~km}$ of the SSL (see Figure 1). Ozone was measured continuously using a TECO model 49 analyzer. The photoactive halogen detector, a new method for measuring photoactive halogens, is described in detail by Impey et al. [this issue]. Briefly, the technique involves drawing the sample air through a $\sim 2 \mathrm{~L}$ cylindrical pyrex reaction vessel at $\sim 1 \mathrm{~L} / \mathrm{min}$ (i.e., 


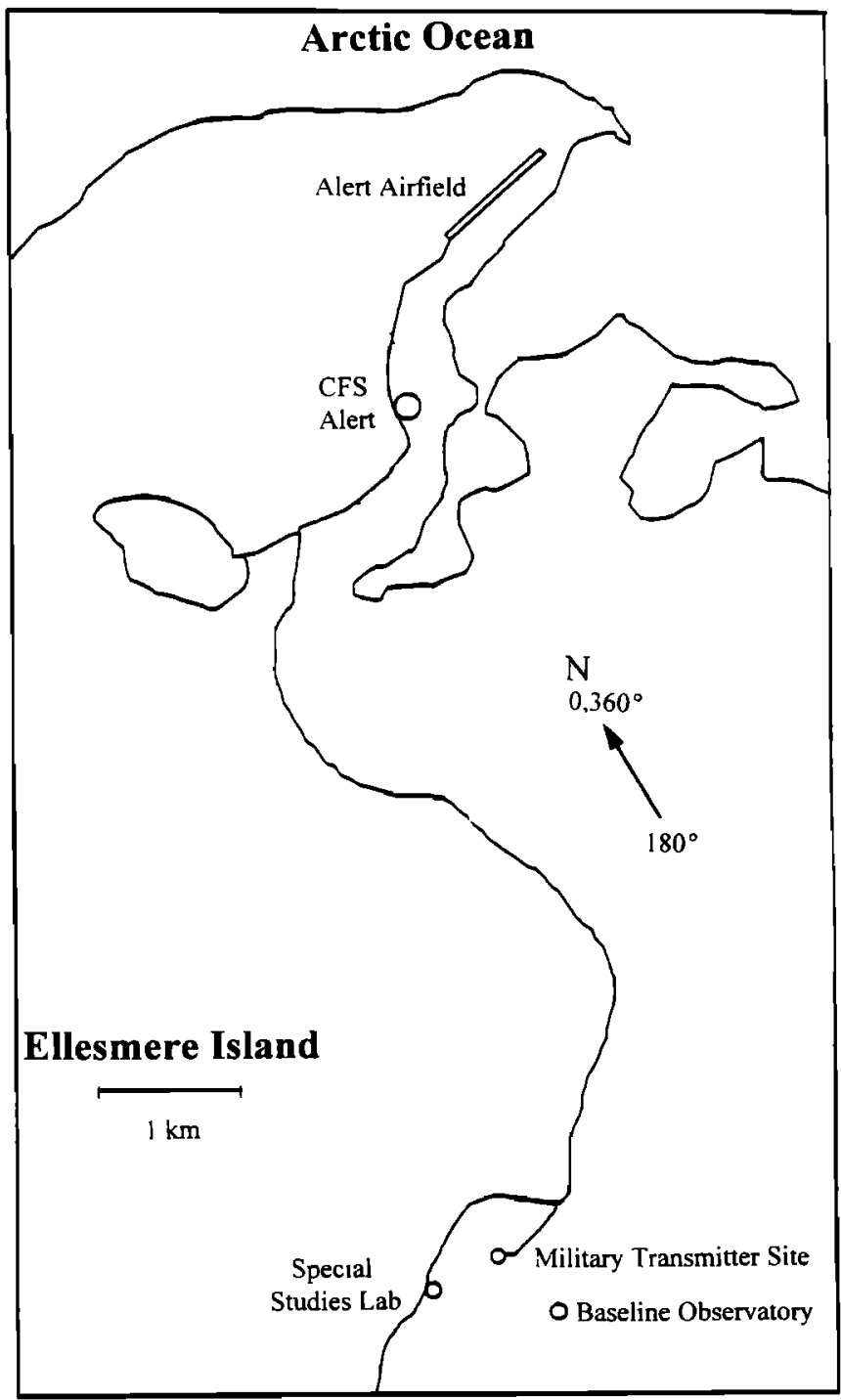

Figure 1. Map of the northern tip of Ellesmere Island. Sampling took place at the Special Studies Laboratory. Ozone was measured continuously from the Baseline Observatory.

a reactor residence time of $2 \mathrm{~min}$ ). Irradiation of the sample air in the reaction vessel using a $150 \mathrm{~W}$ xenon arc lamp photolyzes the ambient $\mathrm{Cl}_{2}$ and $\mathrm{Br}_{2}$ (and other photolytically active halogen molecules, such as $\mathrm{HOCl}, \mathrm{HOBr}, \mathrm{CINO}, \mathrm{BrNO}, \mathrm{ClNO}_{2}, \mathrm{BrNO}_{2}$, $\mathrm{ClONO}_{2}$, and $\mathrm{BrONO}_{2}$ ), to yield free $\mathrm{Cl}$ and $\mathrm{Br}$ atoms. These $\mathrm{Cl}$ and $\mathrm{Br}$ atoms then react rapidly in the cell with added propene $\left(\mathrm{C}_{3} \mathrm{H}_{6}\right)$ and nitric oxide (NO) to produce, among other products, chloroacetone and bromoacetone. These reaction products are concentrated from $36 \mathrm{~L}$ reactor samples onto small adsorbentfilled tubes, extracted, and then measured using capillary gas chromatography with electron capture detection. The system is calibrated through the preparation of low concentration mixtures of $\mathrm{Cl}_{2}$ and $\mathrm{Br}_{2}$ in air and sampling these mixtures at the reactor inlet. The method then' measures photolytically active $\mathrm{Cl}$ and $\mathrm{Br}$ sources, "as $\mathrm{Cl}_{2}$," and "as $\mathrm{Br}_{2}$." The detection limits (for a $36 \mathrm{~L}$ sample) for $\mathrm{Cl}_{2}$ and $\mathrm{Br}_{2}$ are 9 pptv and 4 pptv, respectively.

\section{Results and Discussion}

Measured ground level ozone and the total photolyzable chlorine concentrations as $\mathrm{Cl}_{2}$ and the total photolyzable bromine

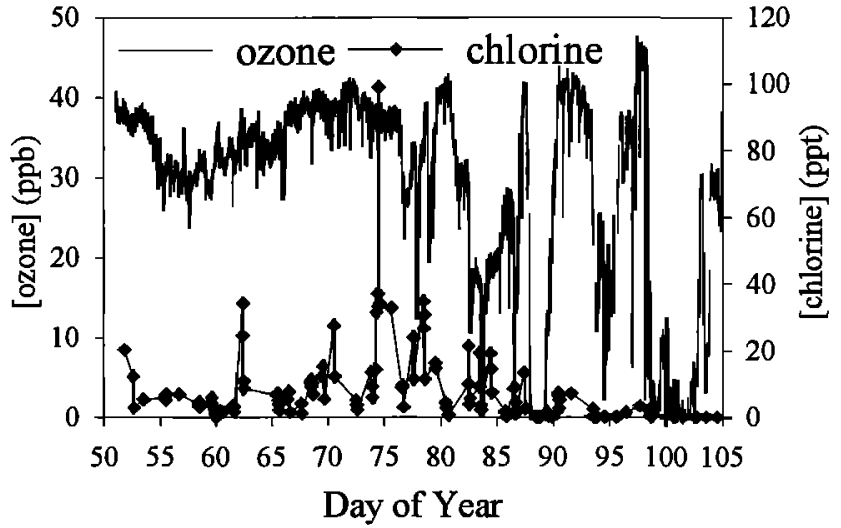

Figure 2. Comparison of ground level ozone and photolyzable chlorine as $\mathrm{Cl}_{2}$, measured at Alert.

as $\mathrm{Br}_{2}$ at Alert are shown in Figures 2 and 3. One hour integrated samples were collected for the period between February 20 and April 14 (days 51-104). This period represents a good sampling for the transition from complete 24 hours of darkness to complete 24 hours of light. March 4 (day 63) was the first day the Sun was visible above the horizon (for a total time of $\sim 15 \mathrm{~min}$ ). By day 80 the Sun was visible for approximately 8 hours, highest in the sky over Alert at about 1110 LT. Measurements of photolyzable chlorine beyond this day were either low or below the detection limit of the instrument. In contrast, and interestingly, significant concentrations of photolyzable bromine were present after sunrise, even though either likely measured bromine compound $\left(\mathrm{Br}_{2}\right.$ or $\left.\mathrm{HOBr}\right)$ has a substantially shorter photolytic lifetime than the corresponding chlorine compound.

The PHD will respond to a number of atmospheric halogen species as noted above. However, their individual contributions to the system response can be very region dependent. As discussed by Shepson et al. [1996] the Arctic at sunrise is likely to be an extremely low [ $\mathrm{NO}_{x}$ ] environment, which can help rule out some possibilities. Specifically, formation of $\mathrm{ClNO}, \mathrm{ClNO}_{2}$, $\mathrm{ClONO}_{2}$, and similar nitrogen-containing bromine species is unlikely to be important in this particular environment. The PHD will not exhibit a significant response to $\mathrm{HCl}(\mathrm{HBr})$ or any organohalogen species. Thus, given what is currently known about the atmospheric chemistry of chlorine and bromine, we assume that $\mathrm{Cl}_{2}$ and $\mathrm{HOCl}$, and $\mathrm{Br}_{2}$ and $\mathrm{HOBr}$ make up the measured $\mathrm{Cl}_{\mathrm{p}}$ and $\mathrm{Br}_{\mathrm{p}}$, respectively.

For March 14 and 15 (days 73-74) we conducted several measurements over the full diel cycle; the results are shown in

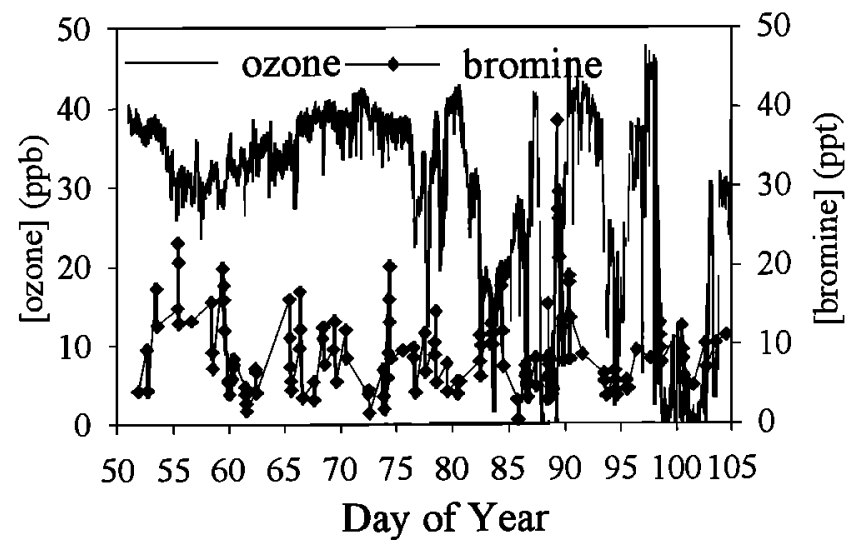

Figure 3. Comparison of ground level ozone and photolyzable bromine as $\mathrm{Br}_{2}$, measured at Alert. 


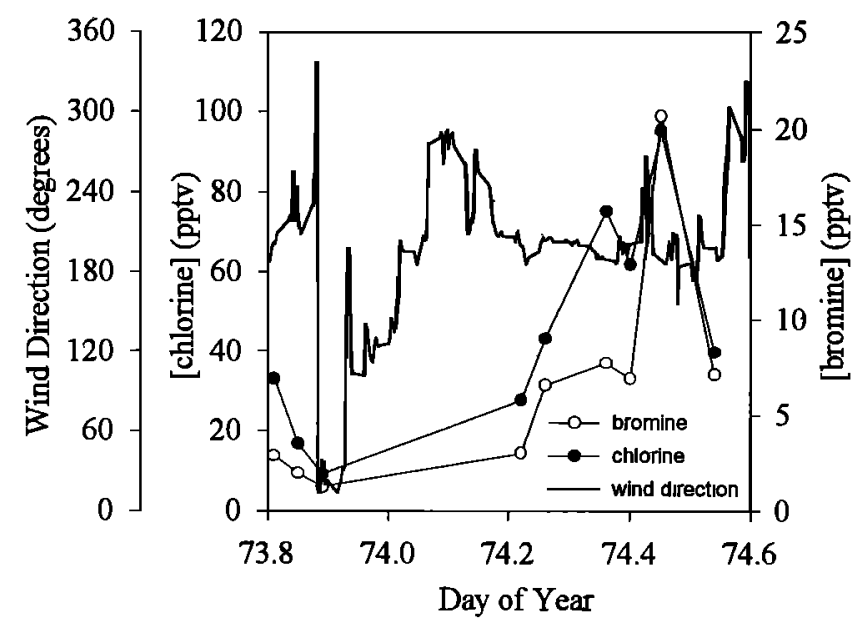

Figure 4a. Wind direction and a complete diel cycle showing the diumal trend for both chlorine and bromine on days 73-74.

Figure 4a. These data show a distinct and similar diurnal cycle for both photolyzable chlorine and bromine, with a maximum near 1100 LT and a minimum near midnight. In Figure $4 \mathrm{~b}$ we present the average diurnal chlorine and bromine concentrations for all the data obtained for days 63-91. This period is chosen as the period after sunrise where the chlorine concentrations were above the detection limit. The average diurnal profile is similar to that shown in Figure 4a, i.e., a late morning maximum and a minimum near midnight. This is in contrast to what we might expect for rapidly photolyzable species, i.e., low concentrations during the day and high at night. The fact that both chlorine and bromine exhibit similar diurnal characteristics with maxima in the daytime might implies a photo-induced (possibly heterogeneous) source, e.g., as postulated by McConnell et al. [1992] and McConnell and Henderson [1993]. However, the presence of substantial concentrations of both species well before sunrise (before day 63) clearly indicates that there must be a dark mechanism for their formation. Several cases for which $\mathrm{Br}_{\mathrm{p}}$ is high in the dark (e.g., days 55-60) occur when the back trajectories show the air arriving at Alert from an Arctic oceanic origin and thus are not likely to have been sunlit. The wind direction data shown for the one case in Figure 4a imply a change

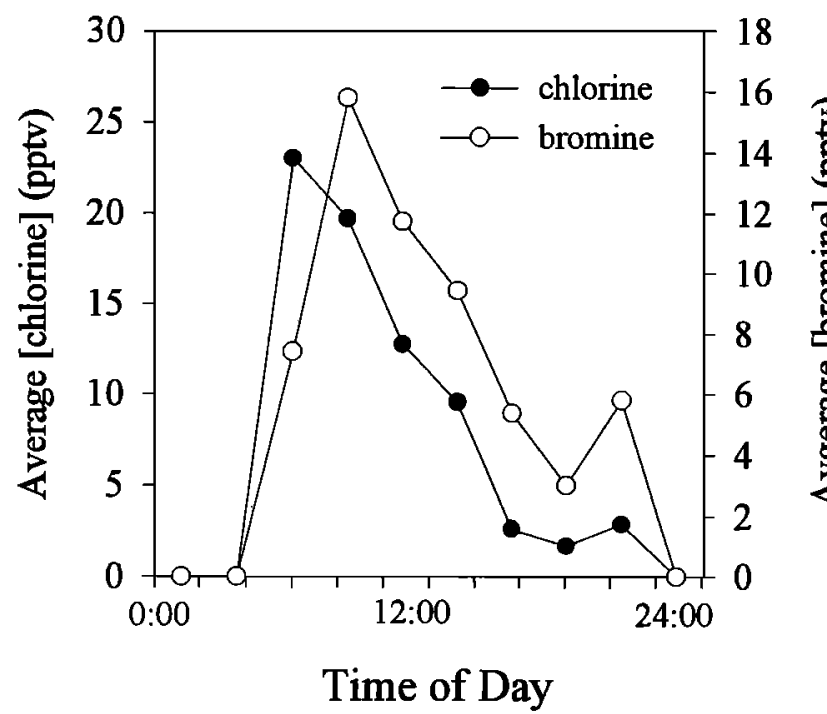

Figure 4b. Average diurnal chlorine and bromine concentrations for days 63-80. from an oceanic origin to an origin from the Baffin Inlet direction when chlorine and bromine concentrations were highest. However, as discussed below, only the chlorine data indicate that elevated levels appear to be typically correlated with trajectories originating from the Baffin Inlet region. Over the entire sampling period, chlorine and bromine were not well correlated (slope of 0.05 and $R^{2}=0.026$ for a regression of chlorine against bromine).

There are several potential mechanisms for production of photolytically active chlorine and bromine species in the dark. Taube [1942] showed that $\mathrm{Br}^{-}$reacts readily in solution with dissolved ozone (similarly for $\mathrm{Cl}^{-}$[Yeatts and Taube, 1949]), followed by a rapid protonation to produce $\mathrm{HOBr}$. $\mathrm{HOBr}$ can then oxidize condensed phase $\mathrm{Br}^{-}$to $\mathrm{Br}_{2}$, as shown in (R3), [Eigen and Kustin, 1962; Fan and Jacob, 1992]:

$$
\begin{array}{ll}
(\mathrm{R} 1) \mathrm{O}_{3}+\mathrm{Br}^{-} & \rightarrow \mathrm{OBr}^{-}+\mathrm{O}_{2} \\
(\mathrm{R} 2) \mathrm{OBr}^{-}+\mathrm{H}^{+} & \rightleftharpoons \mathrm{HOBr}_{(\mathrm{aq})} \\
(\mathrm{R} 3) \mathrm{HOBr}_{(\mathrm{aq})}+\mathrm{Br}^{-}+\mathrm{H}^{+} & \rightarrow \mathrm{Br}_{2}+\mathrm{H}_{2} \mathrm{O}
\end{array}
$$

Similarly, Mozurkewich [1995] suggested that peroxymonosulfuric acid, produced through a free radical chain oxidation of dissolved S(IV) species, could also oxidize bromide ions to $\mathrm{HOBr}$, as shown in (R4). This would then be followed by $\mathrm{Br}_{2}$ production through (R3).

$$
\text { (R4) } \mathrm{HSO}_{5}^{-}+\mathrm{Br}^{-} \rightarrow \mathrm{SO}_{4}^{-2}+\mathrm{HOBr}_{(\mathrm{aq})}
$$

This requires low temperatures and high $\mathrm{SO}_{2}$, concentrations which exist only during the winter and early spring in the Arctic region. Zetzsch et al. [1988] and Zetzsch and Behnke [1993] have found that $\mathrm{O}_{3}$ can react with $\mathrm{HCl}$ on aerosol surfaces to produce $\mathrm{Cl}_{2}$ in the dark but that the heterogeneous production of $\mathrm{Cl}_{2}$ can be photocatalyzed. It has been reported by Livingston and Fintayson-Pitts [1991] and by Zetzsch and Beinke [1993] that reaction of $\mathrm{N}_{2} \mathrm{O}_{5}$ with $\mathrm{NaCl}(\mathrm{s})$ can produce $\mathrm{NO}_{2} \mathrm{Cl}$, which subsequently photolyzes to yield $\mathrm{Cl}$ atoms. However, as discussed by Shepson et al. [1996], and as shown by Honrath and Jaffe [1992], the levels of available $\mathrm{NO}_{x}$ in the Arctic at sunrise should be very low. It has been recently discussed by Tang and McConnell [1996] that only a small $\mathrm{Br}$ atom initiation source (e.g., photolysis of $\mathrm{CHBr}_{3}$ ) is necessary for significant rates ofproduction of $\mathrm{Br}_{2}$ after sunrise, if the Fan and Jacob [1992] mechanism (reaction (R3)) is operative, since that mechanism is autocatalytic. It thus seems possible that the Fan and Jacob mechanism could be operative in the dark but that it is accelerated (at least for bromine) after sunrise.

The Fan and Jacob [1992] mechanism involves conversion of gas phase XO to HOX, via (R5) and (R6), followed by uptake of
(R5) $X$
$+\mathrm{O}_{3}$
$\rightarrow \mathrm{XO}$
$+\mathrm{O}_{2}$
(R6) $\mathrm{XO}$
$+\mathrm{HO}_{2}$
$\rightarrow \mathrm{HOX}+\mathrm{O}_{2}$

the HOX into the acidic aqueous fine aerosol. Since this mechanism not only destroys $\mathrm{O}_{3}$ but also requires its presence, it is instructive to examine the relationship between our measurements of the photolytically active halogen species and $\mathrm{O}_{3}$. Although photolyzable chlorine was not well correlated with ozone over the entire study, the maximum observed photolyzable bromine concentration ( 38 pptv as $\mathrm{Br}_{2}$ ) occurred during the first major $\mathrm{O}_{3}$ depletion episode between days 87 and 90 and was inversely correlated with $\mathrm{O}_{3}$ during this event. An expanded view of the comparison between ozone and bromine concentrations between days 76 and 92 is shown in Figure 5. 


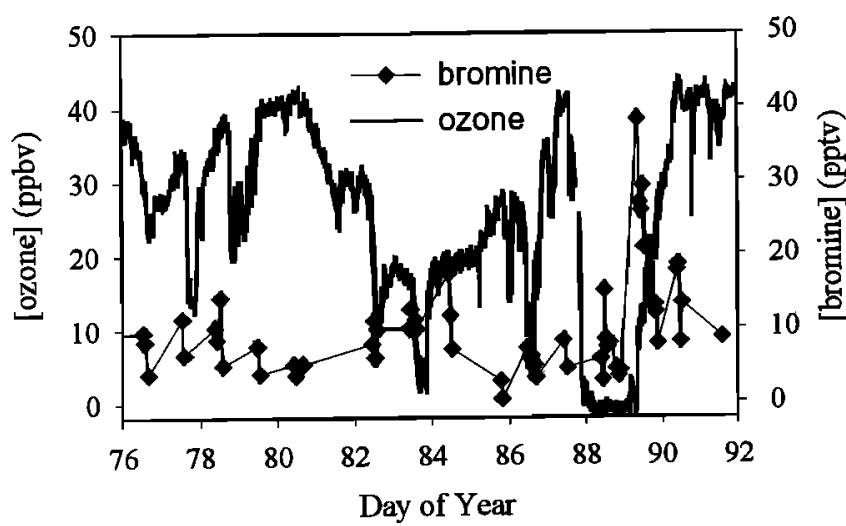

Figure 5. An expanded view for the comparison of ground level ozone and photolyzable bromine for days 76-92.

Three-day back trajectory analysis indicates the sample air arriving from the Arctic ocean region along the north coast of Greenland, in the general direction of Spitsbergen, implying an Arctic source for the photolytically active bromine.

To examine in more detail the origin of high concentrations of the photolytically active halogens, back trajectories were obtained for the end point corresponding to the time of each sample. We then plotted the results as polar plots of [halogen] versus the trajectory origin sector. We arbitrarily divided the back trajectory origins into six equal $45^{\circ}$ intervals and determined the average chlorine and bromine concentrations within each sector. The results are presented in Figures $6 \mathrm{a}$ and $6 \mathrm{~b}$, for bromine and chlorine, respectively. On average the highest bromine concentrations were observed for air parcels arriving at Alert from sector 6 (see Figure 6a). This is interesting in light of the Mozurkewich [1995] mechanism and the fact that this trajectory origin is also associated with the highest levels of $\mathrm{SO}_{2}$ [cf. Barrie et al., 1989]. Unlike bromine, the high chlorine concentrations were observed mainly in the dark period during the earlier part of the study and were from southerly air mass trajectories (sector 1) through the Baffin Inlet (see Figure 6b). Given the fact that $\mathrm{Br}_{2}$ has a photolytic lifetime ( 1-2 min) that is much shorter than that for $\mathrm{Cl}_{2}$ (the same is true for $\mathrm{HOBr}$ relative to $\mathrm{HOCl}$ ), it is interesting that $\mathrm{Br}_{\mathrm{p}}$ is present in significant concentrations after sunrise, while $\mathrm{Cl}_{\mathrm{p}}$ is not. These observations imply that there may be distinctly different production mechanisms for photolytically active chlorine and bromine. This conclusion supports the hypothesis of Shepson et al. [1996] that the levels of aldehydes in the Arctic ocean region are consistent with $\mathrm{Cl}$ atom chemistry occurring in the absence of $\mathrm{Br}$ atom chemistry.

To sustain the observed levels of " $\mathrm{Br}_{2}$ " after sunrise would require a very large source or a continuous recycling from reservoir species like $\mathrm{HBr}, \mathrm{HOBr}$ and $\mathrm{BrONO}_{2}$ as in the Fan and Jacob [1992] mechanism. As discussed above, for the mechanism of Fan and Jacob [1992], the production of $\mathrm{Br}$ atoms will cease in the absence of $\mathrm{O}_{3}$, since there is no means of producing BrO. This is in fact consistent with our observations for the major ozone depletion event of days 88-89. As shown in Figure 5, while $\mathrm{Br}_{\mathrm{p}}$ was close to the detection limit when ozone was completely removed (day 88 ), it was observed to increase at the end of this event, when ozone was increasing to typical unperturbed levels (note that we were not sampling during the start of this $\mathrm{O}_{3}$ depletion event). This observation is also consistent with preliminary results from the ARCTOC field

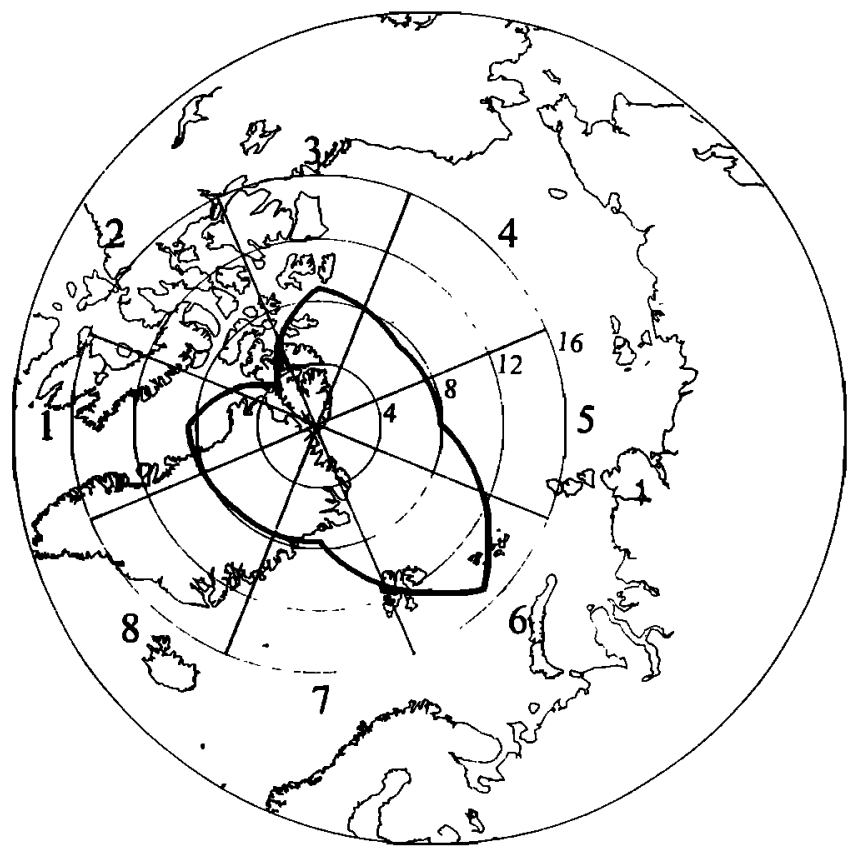

Figure 6a. Average bromine concentration ( $0-16 \mathrm{pptv})$ by sector region.

campaign in Ny-Ålesund, Spitsbergen (in April 1995) [(H. Lorenzen-Schmidt et al., unpublished manuscript, 1995)] during which significant levels of BrO (as much as $\sim 40$ pptv) were observed on the wings of the ozone depletion episodes. It should be noted that there is only a small period of time when we would expect a good correlation between photolyzable bromine and ozone, i.e., only after sunrise when ozone depletion chemistry occurs but before the solar flux is so large that the lifetime of $\mathrm{Br}_{\mathrm{p}}$ becomes too small to sustain high $\mathrm{Br}_{\mathrm{p}}$ levels.

Since our method does not discriminate between $\mathrm{Br}_{2}$ and $\mathrm{HOBr}$ (or $\mathrm{Cl}_{2}$ and $\mathrm{HOCl}$ ), we examined the importance of the different photochemically active sources, using a simple box

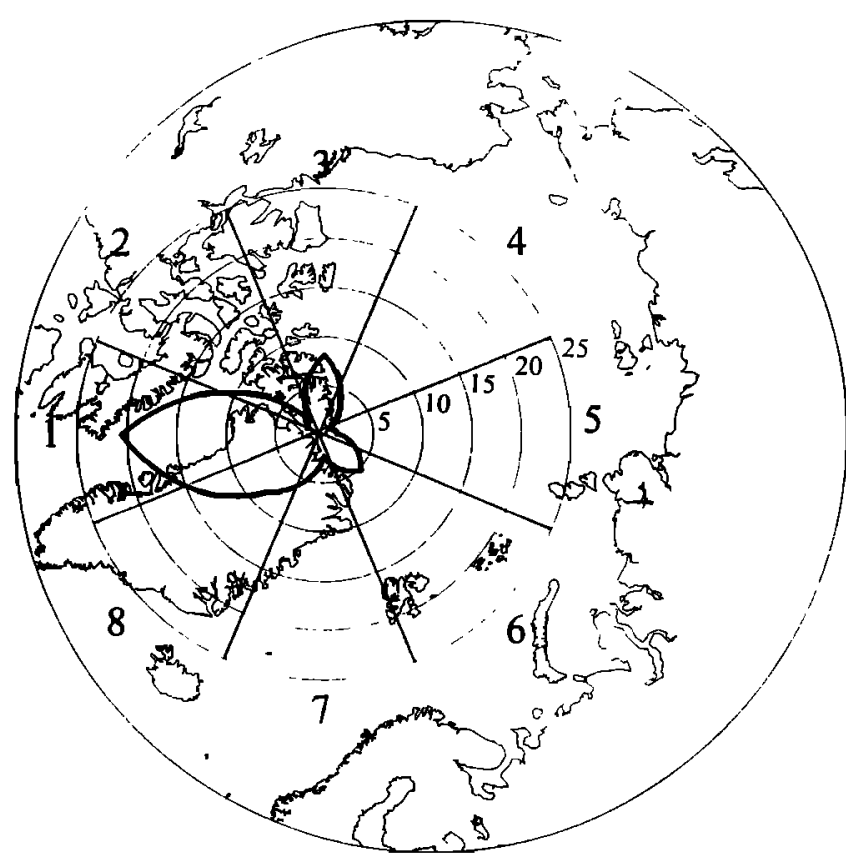

Figure 6b. Average chlorine concentration (0-25 pptv) by sector region. 
model. The model contains 78 reactions with 49 species, including the standard gas phase $\mathrm{ClO}_{x}, \mathrm{BrO}_{x}, \mathrm{NO}_{x}$, and $\mathrm{HO}_{x}$ chemistry. Constant $\mathrm{Br}_{2}$ and $\mathrm{Cl}_{2}$ fluxes of $22 \mathrm{pptv} / \mathrm{h}$ and $6 \mathrm{pptv} / \mathrm{h}$, respectively, are used to maintain the $\mathrm{Br}$ and $\mathrm{Cl}$ atom concentrations at $10^{7}$ and $10^{4}$ molecules $/ \mathrm{cm}^{3}$, respectively, in accord with the estimates of Jobson et al. [1994]. Photodissociation rate coefficients are as used in the modeling study of Tang and McConnell [1996] (with an update for $\mathrm{HOBr}$ photolysis from Lock et al. [1996]). Concentrations of formaldehyde $(\mathrm{HCHO})$ and acetaldehyde $\left(\mathrm{CH}_{3} \mathrm{CHO}\right)$, which are major sinks for $\mathrm{Br}$ atoms, are maintained at $200 \mathrm{pptv}$ and 100 pptv, respectively [Shepson et al., 1996]. Also, all relevant hydrocarbon, $\mathrm{NO}_{x}$ and $\mathrm{O}_{3}$ initial concentrations are consistent with measurements from PSE 1992 [see Barrie et al., 1994] and with the measurements conducted at Alert in 1995.

The input conditions discussed above simulate the observed ozone decay. The model predicts a steady state concentration of $\approx 0.5 \mathrm{pptv}$ for $\mathrm{Br}_{2}$. The simulated $\mathrm{HOBr}$ concentration depends on the value for the effective first-order transfer coefficient for $\mathrm{HOBr}$ accommodation into the fine aerosol. Using the value of $1.4 \times 10^{-4} \mathrm{~s}^{-1}$ used by Fan and Jacob [1992] results in an $\mathrm{HOBr}$ concentration, when $\mathrm{O}_{3}$ is present, of only $\approx 10$ pptv. However, laboratory measurements by Abbatt [1994] indicate that the uptake coefficient is considerably larger than that $(0.01)$ used by Fan and Jacob. If we use an upper limit uptake coefficient for $\mathrm{HOBr}$ of 1 , the first-order transfer coefficient would be $2.2 \times 10^{-3}$ $\mathrm{s}^{-1}$, using the method described by Sander and Crutzen [1996]. This value then results in a simulated $\mathrm{HOBr}$ concentration of only $\approx 1$ pptv. That $[\mathrm{HOBr}]>\left[\mathrm{Br}_{2}\right]$ results from the fact that $\mathrm{Br}$ atoms are relatively efficiently converted to $\mathrm{HOBr}$ via (R5) and (R6) and because $\mathrm{Br}_{2}$ photolysis is $25-30$ times faster than that for HOBr.

To examine the relative effects of photolytically active bromine in the form of $\mathrm{Br}_{2}$ or $\mathrm{HOBr}$, we can convert our measurements of total photolyzable bromine from "as $\mathrm{Br}_{2}$ " to "as $\mathrm{HOBr}$ ". Taking into account the different photolysis rates of $\mathrm{Br}_{2}$ and $\mathrm{HOBr}$ and the residence time within the photoactive halogen detector (PHD), as discussed by Impey et al. [this issue], we find that ["as $\mathrm{HOBr}$ "] $=3.4 \cdot$ ["as $\mathrm{Br}_{2}$ "], so that the $38 \mathrm{pptv}$ "as $\mathrm{Br}_{2}$ " observed on day 89 is the equivalent of 129 pptv "as HOBr". Similarly, ["as $\left.\mathrm{HOCl}^{\prime \prime}\right]=5.0 \cdot$ ["as $\mathrm{Cl}_{2}$ "]. Although our measurements during PSE 95 did not allow us to discriminate between $\mathrm{Br}_{2}$ and $\mathrm{HOBr}$, it is important to do so, as ambient $\mathrm{Br}_{2}$ photolysis produces $\mathrm{Br}$ atoms $\approx 50$ times faster than does an identical concentration of $\mathrm{HOBr}$. Thus for day 89 we calculate that $38 \mathrm{ppt}$ of $\mathrm{Br}_{2}$ will result in a photolytic $\mathrm{Br}$ atom production rate of $2.7 \times 10^{7}$ molecules $/ \mathrm{cm}^{3} \cdot \mathrm{s}$, while $129 \mathrm{ppt}$ of $\mathrm{HOBr}$ would produce only $1.7 \times 10^{6}$ molecules $/ \mathrm{cm}^{3} \cdot \mathrm{s}$.

As discussed by Jobson et al. [1994] and Shepson et al. [1996], the relative rates of decay of various reactive hydrocarbons (e.g., alkanes and acetylene; aldehydes and ketones) are highly dependent on the $[\mathrm{Br}] /[\mathrm{Cl}]$ ratio. For days when there is radiation and when the photolytically active halogens are well above the detection limit, it is possible to estimate the resulting steady state $\mathrm{Br}$ and $\mathrm{Cl}$ atom concentrations. A good case for this is day 83 , when the ozone concentration ranged between $\approx 5-20 \mathrm{ppb}$. Using the measured maximum concentrations on day 83 of 43 and $97 \mathrm{pptv}$ of $\mathrm{HOBr}$ and $\mathrm{HOCl}$, respectively (i.e., assuming these represent $\mathrm{Br}_{\mathrm{p}}$ and $\mathrm{Cl}_{\mathrm{p}}$ ), a steady state concentration of $\mathrm{Br}$ and $\mathrm{Cl}$ atoms can be estimated from equations (1) and (2):

$$
[\mathrm{Br}]=\frac{J_{\mathrm{HOBr}}[\mathrm{HOBr}]}{k_{\mathrm{Br}}\left[\mathrm{O}_{3}\right]+k_{\mathrm{Br}}[\mathrm{HCHO}]+k_{\mathrm{Br}}\left[\mathrm{CH}_{3} \mathrm{CHO}\right]+k_{\mathrm{Br}}\left[\mathrm{C}_{2} \mathrm{H}_{2}\right]}
$$

$$
\begin{aligned}
& {[\mathrm{Cl}]=\frac{J_{\mathrm{HOCl}}[\mathrm{HOCl}]}{k_{\mathrm{Cl}}\left[\mathrm{O}_{3}\right]+k_{\mathrm{Cl}}[\mathrm{HCHO}]+k_{\mathrm{Cl}}\left[\mathrm{CH}_{3} \mathrm{CHO}\right]}} \\
& \left.+k_{\mathrm{Cl}}\left[\mathrm{CH}_{4}\right]+\sum k_{\mathrm{Cl}(i)}[\mathrm{RH}]\right\}
\end{aligned}
$$

Here $k_{x}$ corresponds to the rate constant for $\mathrm{Br}$ or $\mathrm{Cl}$ atom reaction with that particular reacting species. The last term in the denominator of equation (2) includes all alkanes from $C_{2}$ to $C_{8}$, as well as $\mathrm{C}_{2} \mathrm{H}_{4}, \mathrm{C}_{3} \mathrm{H}_{6}$, and $\mathrm{C}_{2} \mathrm{H}_{2}$. $\mathrm{Br}$ atoms are assumed to be removed only through reaction with $\mathrm{O}_{3}, \mathrm{HCHO}, \mathrm{CH}_{3} \mathrm{CHO}$, and $\mathrm{C}_{2} \mathrm{H}_{2}$. Corresponding calculated values for $\mathrm{Br}$ and $\mathrm{Cl}$ atom concentrations can be obtained assuming that the measured photolytically active species are $\mathrm{Br}_{2}$ and $\mathrm{Cl}_{2}$, by appropriate substitution, e.g., of $J_{\mathrm{Br}_{2}} \cdot\left[\mathrm{Br}_{2}\right]$ into the numerator of equation (1). Using our estimates for the $J$ values, and the measured hydrocarbon data at Alert, the calculated steady state $\mathrm{Br}$ atom concentration for the day 83 episode is between $1.0 \times 10^{6}$ atoms $/ \mathrm{cm}^{3}$ (assuming the precursor is $\mathrm{HOBr}$ ) and $1.8 \times 10^{7}$ atoms $/ \mathrm{cm}^{3}$ (assuming it is $\mathrm{Br}_{2}$ ). The corresponding values for $[\mathrm{Cl}]$ are $1.0 \times 10^{4}$ atoms $/ \mathrm{cm}^{3}(\mathrm{HOCl})$ and $6.1 \times 10^{4}$ atoms $/ \mathrm{cm}^{3}\left(\mathrm{Cl}_{2}\right)$. Because of the large range of estimated values, we can only say that our estimates for the absolute concentrations are consistent with the estimates of Jobson et al. [1994]. However, the calculated ratio $[\mathrm{Br}] /[\mathrm{Cl}]$ is much less sensitive to the identity of the precursor, i.e., we obtain $[\mathrm{Br}] /[\mathrm{Cl}] \approx 100$ if the precursors are $\mathrm{HOBr}$ and $\mathrm{HOCl}$, and $\approx 300$ if the precursors are $\mathrm{Br}_{2}$ and $\mathrm{Cl}_{2}$. This range of $[\mathrm{Br}] /[\mathrm{Cl}]$ atom ratios is slightly lower than the Jobson et al. [1994] estimate of about 800 . This result may, however, depend on the availability of ozone in the air mass (see discussion above) and could be quite variable. For example, if we assume the measured photolyzable chlorine concentration on day 89 (a maximum $\mathrm{HOBr}$ of $129 \mathrm{ppt}$ ) to be $\sim 9 \mathrm{pptv}$ as $\mathrm{Cl}_{2}$ (i.e., at the detection limit, corresponding to $45 \mathrm{ppt} \mathrm{HOCl}$ ), the calculated (steady state) $[\mathrm{Br}] /[\mathrm{Cl}]$ ratio has an upper limit of approximately 2000 . Thus we can only say that the $\mathrm{Br} / \mathrm{Cl}$ atom ratio appears to be consistent with the estimates of Jobson et al. [1994].

Our model predicts a maximum $\mathrm{HOBr}$ concentration ranging between 1 and $10 \mathrm{pptv}$ (when $[\mathrm{Br}]$ is fixed near the Jobson et al. [1994] estimate of $10^{7}$ ), but our measurements indicate that as much as $129 \mathrm{pptv}$ of $\mathrm{HOBr}$ may be present during an ozone depletion episode when we are sampling air from the Arctic ocean region. Increasing the $\mathrm{Br}_{2}$ flux in the model to as much as $170 \mathrm{pptv} / \mathrm{h}$ (yielding a simulated $[\mathrm{Br}]$ near the upper limit of the literature estimates of $6 \times 10^{7}$ atoms $/ \mathrm{cm}^{3}$ ) still produces only 40 pptv of HOBr. The Fan and Jacob [1992] mechanism involves uptake of $\mathrm{HOBr}$ onto acidic aerosol that contains $\mathrm{Br}^{-}$, followed by (R3). One test of this mechanism is to compare the estimated $\mathrm{Br}_{2}$ production rate with the amount of available aerosol bromine. If the $\mathrm{Br}_{2}$ is generated from (R3), the lifetime of bromine in the aerosol would then be given by $\tau_{\text {aerosol } \mathrm{Br}}=$ [aerosol $\mathrm{Br}] / 2 \cdot\left[\mathrm{Br}_{2}\right.$ flux]. Using the $L i$ et al. [1994] measured aerosol $\mathrm{Br}$ concentration of about $1.25 \times 10^{-9} \mathrm{~mol} \mathrm{Br} / \mathrm{m}^{3}$ during an ozone depletion event when air was coming from the Arctic ocean boundary layer and assuming a $\mathrm{Br}_{2}$ production rate from the aerosol of $170 \mathrm{pptv} / \mathrm{h}\left(2.82 \times 10^{-10} \mathrm{~mol} \mathrm{Br} / \mathrm{m}^{3} \mathrm{~min}\right)$ leads to an effective lifetime for the aerosol $\mathrm{Br}$ of 2.2 minutes. However, following the method of Sander and Crutzen [1996], our estimated characteristic time for gas-phase diffusion of the limiting reactant $\mathrm{HOBr}$ to the aerosol surface is $8 \mathrm{~min}$ (using an average particle radius of $1.5 \times 10^{-5} \mathrm{~cm}$, an accommodation coefficient $\alpha$ of 1 , and dimensionless LWC $=4 \times 10^{-12}$ [Staebler et al., 1994]). Using this value for $\alpha$ yields the lower limit to the $\mathrm{HOBr}$ characteristic transport time to the aerosol. However, 
since our lower limit estimate is greater than the effective aerosol $\mathrm{Br}$ lifetime, it appears that the available aerosol bromine would be rapidly depleted if the only mechanism for generating photolytically active bromine was (R3) occurring on aerosol particles. Therefore it appears that other mechanisms, such as oxidation of $\mathrm{Br}^{-}$in the surface ice [Tang and McConnell, 1996], may play a more important role in generation of photolytically active bromine in the Arctic.

\section{Conclusions}

This work provides conclusive evidence for the presence of substantial concentrations of photolytically active chlorine and bromine in the Arctic near the time of polar sunrise. For both photolytically active chlorine and bromine it is apparent that there exist dark production mechanisms, as large concentrations were observed before sunrise. Furthermore, large concentrations of photolytically active bromine were observed after sunrise, when the lifetime of these species (presumably $\mathrm{Br}_{2}$ or $\mathrm{HOBr}$ ) are short, implying a large source, and indicating a large $\mathrm{Br}$ atom source. For example, for day 89 , the $\sim 38 \mathrm{pptv}$ of bromine ("as $\left.\mathrm{Br}_{2}{ }^{\prime \prime}\right)$ would be equivalent to $3.8 \mathrm{ppbv}$ of $\mathrm{CHBr}_{3}(\approx 3$ orders of magnitude greater than observed) in terms of the relative rates of photolytic generation of $\mathrm{Br}$ atoms. It is thus clear from our data that $\mathrm{CHBr}_{3}$ (or other organo-bromine compounds) is an unimportant source of bromine atoms in the Arctic at polar sunrise.

The observation of high bromine on the "wings" of an ozone depletion episode seems to indicate either that we are measuring $\mathrm{HOBr}$ or that ozone is an important oxidant (or directly related to the oxidant) involved in production of $\mathrm{Br}_{2}$. It is important that the exact nature of this $\mathrm{Br}$ atom source be determined (i.e., $\mathrm{Br}_{2}$ versus $\mathrm{HOBr}$ ).

Acknowledgments. We thank Natural Sciences and Engineering Research Council of Canada and the Atmospheric Environment Service for their financial support and D. Worthy for back trajectories and meterological data. We also thank Jack McConnell and Apollo Tang for helpful discussions.

\section{References}

Abbatt, J.P.D., Heterogeneous reaction of $\mathrm{HOBr}$ with $\mathrm{HBr}$ and $\mathrm{HCl}$ on ice surfaces at 228K, Geophys. Res. Lett., 21, 665-668, 1994.

Barrie, L.A., J.W. Bottenheim, R.C. Schnell, P.J. Crutzen, and R.A. Rasmussen, Ozone destruction and photochemical reactions at polar sunrise in the lower Arctic atmosphere, Nature, 334, 138-141, 1988.

Barrie, L. A., G. Den Hartog, J. W. Bottenheim, and S. Landsberger, Anthropogenic aerosols and gases in the lower troposphere at Alert, Canada in April 1986, J. Atmos. Chem., 9, 101-127, 1989.

Barrie, L.A., J.W. Bottenheim, and W.R. Hart, Polar Sunrise Experiment 1992 (PSE 1992): Preface, J. Geophys. Res., 99, 25,313-25,314, 1994.

Eigen, M., and K. Kustin, The kinetics of halogen hydrolysis, $J$. Am. Chem. Soc., 84, 1355-1361, 1962.

Fan, S.-M. and D.J. Jacob, Surface ozone depletion in Arctic spring sustained by bromine reactions on aerosols, Nature. 359, 522-524, 1992.

Hausmann, M., and U. Platt, Spectroscopic measurement of bromine oxide in the high Arctic during Polar Sunrise Experiment 1992, $J$. Geophys. Res., 99, 25,399-25,413, 1994.

Honrath, R. E., and D. A. Jaffe, The seasonal cycle of nitrogen oxides in the Arctic troposphere at Barrow, Alaska, J. Geophys. Res., 97, 20,615-20,630, 1992

Impey, G.A., P.B. Shepson, D.R. Hastie, L.A. Barrie, Measurement technique for the determination of photolyzable chlorine and bromine in the atmosphere, J. Geophys. Res., this issue.

Jobson, B.T., H. Niki, Y. Yokouchi, J. Bottenheim, F. Hopper, and R. Leaitch, Measurements of C2-C6 hydrocarbons during the 1992 Polar Sunrise Experiment: Evidence of Cl-atom and Br-atom chemistry, $J$. Geophys. Res., 99, 25,355-25,368, 1994.
Keene, W.C., J.R. Maben, A.A.P. Pszenny, and J.N. Galloway, Measurement technique for inorganic chlorine gases in the marine boundary layer, Environ. Sci. Technol. 27, 866-874, 1993.

Li, S.M., Y. Yokouchi, L.A. Barrie, K. Muthuramu, P.B. Shepson, J.W. Bottenheim, W.T. Sturges, and S. Landsberger, Organic and inorganic bromine compounds and their composition in the Arctic troposphere during polar sunrise, J. Geophys. Res., 99, 25,415-25,428, 1994.

Livingston, F. E., and B. J. Finlayson-Pitts, The reaction of gaseous $\mathrm{N}_{2} \mathrm{O}_{5}$ with solid $\mathrm{NaCl}$ at $298 \mathrm{~K}$ : Estimated lower limit to the reaction probability and its potential role in tropospheric and stratospheric chemistry, Geophys. Res. Lett., 18, 17-20, 1991.

Lock, M., R.J. Barnes, and A. Sinha, Near-threshold photodissociation dynamics of $\mathrm{HOBr}$ : determination of product state distribution, vector correlation, and heat of formation, J. Phys. Chem., 100, 7972-7980, 1996.

Maben, J.R., W.C. Keene, A.A.P. Pszenny, and J.N. Galloway, Volatile inorganic $\mathrm{Cl}$ in surface air over eastern North America, Geophys. Res. Lett., 22, 3513-3516, 1995.

McConnell, J.C., and G.S. Henderson, Ozone depletion during polar sunrise, in tropospheric chemistry of ozone in polar regions, Global Environmental Change, edited by $\mathrm{H}$. Niki and K.H. Becker, NATO ASI Ser. I, 7, 89-103, 1993.

McConnell, J.C., G.S. Henderson, L.A. Barrie, J. Bottenheim, H. Niki, C.H. Langford, and E.M. Templeton, Photochemical bromine production implicated in Arctic boundary-layer ozone depletion, Nature, 355, 150-152, 1992.

Mozurkewich, M., Mechanisms for the release of halogens from sea-salt particles by free radical reactions, J. Geophys. Res., 100, 14,19914,207, 1995 .

Muthuramu, K., P.B. Shepson, J.W. Bottenheim, B.T. Jobson, H. Niki, and K.G. Anlauf, Relationships between organic nitrates and surface ozone destruction during Polar Sunrise Experiment 1992, J. Geophys. Res., 99. 25,369-25,378, 1994.

Pszenny, A.A.P., W.C. Keene, D.J. Jacob, S. Fan, J.R. Maben, M.P. Zetwo, M. Springer-Young, and J.N. Galloway, Evidence of inorganic chlorine gases other than hydrogen chloride in marine surface air, Geophys. Res. Lett., 20, 699-702, 1993.

Sander, R., and P. J. Crutzen, Model study indicating halogen activation and ozone destruction in polluted air masses transported to the sea, J. Geophys. Res., 101, 9121-9138, 1996.

Shepson, P.B., A.-P. Sirju, F.J. Hopper, L.A. Barrie, V. Young, H. Nikı, and $H$. Dryfhout, Sources and sinks of carbonyl compounds in the Arctic ocean boundary layer: A polar icefloe experiment, J. Geophys. Res., 101, 21,081-21,089, 1996.

Solberg, S., N. Schmidbauer, A. Semb, and F. Stordal, Boundary-layer ozone depletion as seen in the Norwegian Arctic in spring, $J$. Atmos. Chem., 23, 301-332, 1996.

Staebler, R.M., G. den Hartog, B. Georgi, and T. Düsterdiek, Aerosol size distributions in Arctic haze during the Polar Sunrise Experiment 1992, J. Geophys. Res.. 99, 25,429-25,437, 1994.

Tang, T., and J.C. McConnell, Autocatalytic release of bromine from Arctic snow pack during polar sunrise, Geophys. Res. Lett., 23, 26332636, 1996.

Taube, $\mathrm{H}$., Reactions in solutions containing $\mathrm{O}_{3}, \mathrm{H}_{2} \mathrm{O}_{2}, \mathrm{H}^{+}$and $\mathrm{Br}$. The specific rate of the reaction $\mathrm{O}_{3}+\mathrm{Br}^{-}, J$. Am. Chem. Soc. 64 , 2468-2474, 1942.

Yeatts, R.B., and $H$. Taube, The kinetics of the reaction of ozone and chloride ion in acidic aqueous solution, J. Am. Chem. Soc., 7l, 400, 1949.

Zetzsch, C., and W. Behnke, Heterogeneous reactions of chlorine compounds, in tropospheric chemistry of ozone in polar regions, Global Environmental Change, edited by H. Niki and K.H. Becker, NATO ASI Ser. I. 7, 291-306, 1993.

Zetzsch, C., G. Pfahler and W. Behnke, Heterogeneous formation of chlorine atoms from $\mathrm{NaCl}$ in a photosmog system, J. Aerosol Sci., 19. 1203-1206, 1988.

K. Anlauf and L. A. Barrie, Atmospheric Environment Service, 4905 Dufferin St., Downsview, Ontario, Canada M3H 5T4. (e-mail: len.barrie@ec.gc.ca)

D. R. Hastie and G. A. Impey, Department of Chemistry, York University, Room 124 CCB, 4700 Keele St., North York, Ontario, Canada M3J IP3. (e-mail: hastie@yorku.ca)

P. B. Shepson, Department of Chemistry, Purdue University, 1393 Brown Bldg., West Lafayette, IN 47907-1393. (e-mail: pshepson@chem.purdue.edu)

(Received September 27, 1996; revised February 19, 1997; accepted March 7, 1997.) 